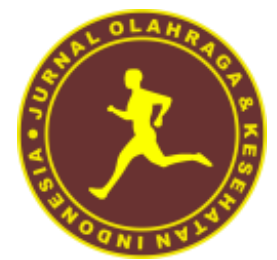

\title{
ANALISIS PERBEDAAN KONTRIBUSI VARIASI LATIHAN PASSING BOLA VOLI
}

\author{
Fajar Sidik Siregar ${ }^{1}{ }^{*}$, Masta Marselina Sembiring ${ }^{2}$, Arifin Siregar ${ }^{3}$ \\ ${ }^{123}$ Universitas Negeri Medan, Sumatera Utara, Indonesia, 20221 \\ *Coressponding Author: fajar.sidik@unimed.ac.id
}

\section{Keterangan}

Rekam Jejak:

Received, April 2021

Revised, Mei 2021

Accepted, Juni 2021

Kata Kunci:

Latihan, Passing, Bola Voli

Penelitian ini bertujuan uuntuk mengetahui bentuk latihan bola volii manakah yang lebih berpengaruh antara bentuk latihan passing atas berpasangan dengan latihan passing ke dinding terhadap hasil passing atas dalam permainan bola voli. Metode penelitian yang digunakan dalam penelitian ini adalah metode experiment, dan pelaksanaan latihan yaitu dengan bentuk latihan passing atas berpasangan dengan passing atas ke dinding. Setelah data terkumpul dilakukan analisis: (1) Analisis hipotesis I peningkatan hasil passing atas kelompok latihan passing atas berpasangan diperoleh $t_{\text {hitung }}$ sebesar 11,09 dan $t_{\text {tabel }}$ sebesar 2,57 dengan $\alpha=0,05$ $\left(t_{\text {hitung }}>\mathrm{t}_{\text {tabel }}\right)$ dimana $(11.09>2.57)$ berarti $\mathrm{H}_{0}$ ditolak dan $\mathrm{H}_{\mathrm{a}}$ diterima. Dapat disimpulkan bahwa terdapat pengaruh yang signifikan dari latihan passing atas berpasangan terhadap hasil passing atas dalam permainan bola voli putra Ekstrakurikuler Bola Voli SMA Negeri 1 Sei Suka Tahun 2020. (2) Analisis hipotesis II peningkatan hasil passing atas kelompok latihan passing atas ke dinding diperoleh $\mathrm{t}_{\text {hitung }}$ sebesar 3.43 serta $\mathrm{t}_{\text {tabel }} 2.57$ dengan $\alpha=0,05\left(\mathrm{t}_{\text {hitung }}>\mathrm{t}\right.$ tabel) dimana $(3.43>2.57)$ berarti $\mathrm{H}_{0}$ ditolak dan $\mathrm{H}_{\mathrm{a}}$ diterima. Dapat disimpulkan terdapat pengaruh yang signifikan dari latihan passing atas ke dinding terhadap hasil passing atas dalam permainan bola voli putra Ekstrakurikuler Bola Voli SMA Negeri 1 Sei Suka Tahun 2020. (3) Analisis hipotesis III dari rata-rata dan simpangan baku diperoleh $\mathrm{t}_{\text {hitung }} 0.11$ serta $\mathrm{t}_{\text {tabel }}$ sebesar 2.23 dengan $\alpha=0,05(\mathrm{t}$ hitung $\left.<\mathrm{t}_{\text {tabel }}\right)$ dimana $(0,11<2.23)$ berarti $\mathrm{H}_{0}$ diterima dan $\mathrm{H}_{\mathrm{a}}$ ditolak. Jadi bentuk latihan passing atas berpasangan tidak lebih besar pengaruhnya dibandingkan dengan latihan passing atas ke dinding terhadap hasil passing atas dalam permainan bola voli putra Ekstrakurikuler Bola Voli SMA Negeri 1 Sei Suka Tahun 2020.
\end{abstract}

Copyright (C) 2020

Jurnal Olahraga \& Kesehatan Indonesia 


\section{PENDAHULUAN}

Bola voli adalah olahraga yang dapat dimainkan oleh anak-anak sampai orang dewasa wanita maupun pria. Menurut Peraturan Permainan Bola Voli (2001-2004:7) menyatakan "bola voli adalah olahraga yang dimainkan oleh dua tim dalam setiap lapangan dipisahkan oleh sebuah net". Tujuan dari permainan bola voli adalah melewatkan bola dari atas net agar dapat jatuh menyentuh lantai lapangan lawan dan untuk mencegah usaha yang sama dari lawan. Setiap tim dapat memainkan tiga pantulan untuk mengembalikan bola (diluar perkenaan block). Dan tim yang memenangkan sebuah reli memperoleh satu angka dan berhak untuk melakukan service, serta para pemainnya melakukan pergerakan satu posisi searah jarum jam. Menurut Muhajir (2006:5), "bola voli adalah permainnan yang dimainkan oleh dua regu yang tiap regu tergiri dari 6 pemain dimana tiap regu berusaha memasukkan bola kedalam daerah lawan agar mendapat angka (point)". Dalam permainan bola voli ada beberapa bentuk teknik dasar yang harus dikuasai seorang pemain bola voli. Menurut Nuril Ahmadi (2007:20) bahwa: "Teknikteknik dalam permainan bola voli terdiri atas service, passing bawah, passing atas block dan smash". Oleh sebab itu, seorang pemain membutuhkan pengetahuan tentang teknik-teknik dasar untuk dapat bermain bola voli secara efektif. Permainan bola voli menerapkan sistem rally point, dimana setiap bola mati akan menghasilkan poin bagi regu yang tidak melakukan kesalahan. Apabila salah satu tim telah memperoleh angka sebanyak 25 poin, maka tim tersebut yang memenangkan pertandingan dalam setiap setnya. Apabila dalam suatu pertandingan kedua regu memperoleh point dua puluh empat sama, maka terjadi selisih dua angka (point). Maksudnya, apabila salah satu regu memperoleh selisih dua point lebih tinggi maka regu tersebut yang memenangkan pertandingan pada set tersebut.

Setiap teknik permainan bola voli memiliki karakteristik gerakan masing-masing, dimana teknik-teknik tersebut menjadi komponen-komponen gerakan dalam permainan bola voli. Passing adalah salah satu teknik dasar bola voli yang paling berpengaruh dalam permainan bola voli dalam hal pertahanan dan pembentukan serangan. Dikarenakan passing menjadi teknik yang mendasar dalam permainan bola voli, maka passing sudah seharusnya menjadi hal pertama yang harus diperhatikan dan dilatih agar dapat melanjutkan dan mengembangkan teknik-teknik selanjutnya agar pemain bola voli dapat bermain lebih baik. Passing juga dapat dilakukan untuk umpan sebagai persiapan serangan yang dilakukan oleh set-up. Barbara L.Viera ( $2000: 19$ ) mengemukakan passing digunakan untuk menerima service,menerima spike,memukul bola setinggi pinggang ke bawah dan memukul bola yang memantul dari net. Passing sendiri terbagi 2 (dua), yaitu passing atas dan passing bawah. Fungsi passing atas (set-up) adalah untuk mengumpan atau memberikan bola kepada smasher. Sedangkan passing bawah berfungsi untuk menahan/menerima bola yang di berikan lawan. Dengan kata lain passing bawah dapat digunakan untuk menerima service, menerima bola smash, memukul bola setinggi pinggang kebawah, membentuk dan membangun serangan serta dapat mengambil bola yang memantul dari net.

Pada dasarnya passing atas adalah bola yang ditangkap di atas, sentuhkan kekening dan lontarkan kembali ke atas, tetapi karena proses gerakan tersebut dilakukan dengan sangat cepat, maka bola terlihat seperti dipantulkan. Cara melakukan passing atas adalah pemain harus belajar bentuk tangan dari teknik passing atas, yaitu meletakkan kedua tangan diatas kepala bersamaan dengan telunjuk dan ibu jari membentuk segitiga, setelah menentukan posisi tangan, pemain akan menyentuh bola di atas mata. Seperti dikatakan oleh Suharno (1983 : 143) teknik pelaksanaan passing atas adalah sebagai berikut "Sikap persiapan mengambil sikap normal, tubuh harus dalam keadaan seimbang yang labil salah satu kaki berada didepan yang lainya, lutut ditekuk, badan agak condong sedikit kedepan dengan tangan siap didepan dada. Pada saat melakukan passing segeralah menempatkan diri dibawah bola dan tangan diangkat keatas kirakira setinggi dahi, jari-jari tangan secara keseluruhan membentuk satu bulatan, jari-jari direnggangkan sedikit satu dengan yang lain, dan kedua ibu jari membentuk satu sudut". 
Latihan adalah proses yang sistematis dari berlatih atau bekerja, yang dilakukan secara berulang-ulang, dengan kian hari kian menambah jumlah beban latihan atau pekerjaannya Harsono, (1988:101). Selanjutnya Bompa (1983:167) berpendapat latihan adalah suatu aktivitas olahraga yang dilakukan secara sistematis dalam waktu yang lama ditingkatkan secara progresif dan individual yang mengarah pada cirri-ciri fungsi fisiologis dan fsikologis untuk mencapai sasaran yang telah ditentukan. Latihan passing atas bola voli merupakan salah satu bentuk latihan untuk meningkatkan dan mengembangkan kemampuan passing atas bola voli yang bentuk latihannya bervariasi dan dilakukan secara berpasangan atau berkelompok dimana dalam pelaksanaannya dilakukan secara berulang-ulang dengan diselingi gerakan maju kedepan, ke samping, ke belakang dirancang sesuai dengan keadaan yang terjadi pada saat melakukan permainan bola voli. Dalam metode variasi latihan, latihan merupakan suatu cara memberikan latihan-latihan terhadap apa yang telah dipelajari siswa sehingga memperoleh suatu keterampilan tertentu.

Harsono (1988:121) menjelaskan variasi latihan yaitu: "Variasi-variasi latihan yang dikreasi dan diterapkan secara cerdik akan dapat menjaga terpeliharanya fisik maupun mental atlet sehingga dengan demikian timbulnya kebosanan dalam berlatih dapat dihindari. Atlet membutuhkan variasi latihan". Sikap permulaan siswa memegang bola dengan dua tangan menghadap ke pasangannya, pelaksanaannya bola dilempar mengarah kepada pasangannya, kemudian bola di passing atas untuk di operkan kepada pasangannya lagi. Jarak keduannya antara 3 meter sampai 4 meter, demikian selanjutnya masing-masing berusaha untuk memasing bola secara berulang-ulang. Pemain 1 melemparkan bola melambung kepada pasangannya, kawan berlatihnya dapat mempassing bola kembali sambil menjatuhkan badan ke kiri dan ke kanan, demikian selanjutnya masing-masing berusaha melempar dan memasing bola secara berulang-ulang. Keuntungan latihan ini adalah siswa tidak mudah jenuh karena mirip dengan bermain sesungguhnya, jadi ada unsure menyenangkan. Sedangkan kelemahannya keajegan bola sulit diantisipasi apabila pasangannya pada saat passing bola kembali bolannya tidak terarah pada pasangannya. Hamalik (Arsyad, 2006:15) mengemukakan bahwa pemakaian media dinding dalam proses belajar mengajar dapat membangkitkan keinginan dan minat yang baru, membangkitkan motivasi dan rangsangan kegiatan belajar, dan bahkan membawa pengaruhpengaruh psikologis terhadap siswa. Adapun fungsi media dinding dalam permainan bola voli adalah sebagai berikut; media pembelajaran dinding yaitu untuk memudahkan para pelatih untuk menyampaikan secara tepat dan efesien kepada siswa, dimana dinding sebagai alat umpan balik dari latihan passing atas bola voli, dan media pembelajaran dinding adalah sebagai alat bantu mengajar yang mempengaruhi kegiatan belajar mengajar dengan fasilitas yang mudah ditemukan khususnya disekolah. Siswa melambungkan bola kedinding berusaha mengambil pantulannya dan memasing bola kembali kedinding sebanyak 5-10 kali demikian seterusnya mempassing bola secara berulang-ulang. Dua orang siswa dengan posisi 1 didepan dan 1 orang pasangannya dibelakang dengan jarak1meter menghadap kedinding, siswa yang dibelakang memasing bola kedinding melewati pasangan didepannya dan siswa yang didepan berusaha mengambil pantulan bola danmemasing atas ke pasangannya belakang secara bergiliran. Demikian selanjutnya dengan berulang-ulang. Keuntungan latihan ini adalah mudah mengantisipasi bola karena tidak terpancang teman pasangannya dan mudah untuk mengukur bola pantul. Sedangkan kelemahannya, karena dinding benda mati maka bila sudut datangnya bola tidak tepat maka hasil pantulannya juga tiidak tepat. Tujuan dari latihan ini adalah untuk melatih reaksi terhadap arah datangnya bola dan menambah kepekaan untuk mengendalikan bola.

\section{METODE}

Sesuai dengan permasalahan dan tujuan penelitian yang di uraikan sebelumnya, bahwa penelitian yang digunakan bermaksud untuk mengetahui apakah terdapat perbedaan pengaruh antara latihan passing atas berpasangan dengan latihan passing atas kedinding terhadap hasil 
passing atas pada siswa putra ekstrakurikuler SMA Negeri 1 Sei Suka Tahun 2020. Berkaitan dengan tujuan penelitian tersebut maka penulis menggunakan metode eksperimen dengan teknik pengumpulan data menggunakan tes dan pengukuran. Eksperimen adalah kegiatan yang dirancang dan dilaksanakan oleh peneliti untuk mengumpulkan bukti-bukti yang ada hubungannya dengan hipotesis.

Data yang telah terkumpul dari pre-test dan post-test dianalisis dengan menggunakan uji normanlitas, uji homogenitas, satistik uji-t dan uji-t gabungan. Membuktikan apakah hipotesis yang diajukan dalam penelitian ini dapay diterima atau ditolak. Untuk menentukan hasil passing atas dengan dibedakan antara latihan passing atas berpasangan dan latihan passing atas ke dinding pada sampel dapat dihitung dalam uji hipotesa, dengan uji-t. untuk menguji hipotesa ditempuh beberapa prosedur statistik dengan mengacu pada buku sudjana (2002.) yaitu uji-t normalitas dan uji homogenitas. Adapun langkah-langkah yang dilakukan adalah sebagai berikut:

- Uji Normalitas

$$
Z i=\frac{X_{i}-\bar{X}}{S}
$$

- Uji Homogenitas

(Sudjana, 2002)

$$
F=\frac{\text { varians terbesar }}{\text { varians terkecil }}
$$

- Mencari Nilai Rata-rata

(Sudjana, 2002)

$$
\bar{X}=\frac{\sum X_{1}}{N}
$$

(Sudjana, 2002)

- Mencari Nilai Rata-rata Beda

$$
\bar{B}=\frac{\sum B_{i}}{n}
$$

(Sudjana, 2002)

- Uji-t

$$
t=\frac{\bar{B}}{s_{B} / \sqrt{n}}
$$

(Sudjana, 2002)

- Mencari Simpangan Baku (S)

$$
S^{2}=\frac{n \sum_{x} 2-\left(\sum x\right)^{2}}{n(n-1)}
$$

(Sudjana, 2005)

- Mencarisimpanganbakubeda (B)

$$
s_{B}^{2}=\frac{n \Sigma B^{2}-(\Sigma B)^{2}}{n(n-1)}
$$

(Sudjana, 2005) 
- Mencari Simpangan Baku Gabungan

$$
S_{\text {Gab }}^{2}=\frac{\left(n_{1}-1\right) S_{1}^{2}+\left(n_{2}-1\right) S_{2}^{2}}{n_{1}+n_{2}-2}
$$

(Sudjana2002:239)

- Mencari $\mathrm{t}_{\mathrm{Hitung}}$

$$
t=\frac{\bar{X}_{1}-\overline{X_{2}}}{S \sqrt{\frac{1}{n_{1}}+\frac{1}{n_{2}}}}
$$

(Sudjana2002 : 239)

Selanjutnya kriteria pengukuran hipotesis sebagai berikut:

$H_{o}$ diterimadan $H_{a}$ ditolakjikat $t_{\text {hitung }}<t_{1-1 / 2}{ }^{a}$ pada taraf signifikan $\alpha=0,05$

$H_{o}$ ditolakdan $H_{a}$ diterimajikat $t_{\text {hitung }}>t_{1-1 / 2}{ }^{a}$ pada taraf signifikan $\alpha=0,05$

Pada syarat uji data harus normal (uji normalitas) $\&$ homogen (uji homogenitas).

\section{HASIL \& PEMBAHASAN}

Hasil tes dan pengukuran yang telah dilakukan di lapangan merupakan temuan peneliti yang dilakukan selama 5 minggu. Dilakukan untuk mengungkapkan kebenaran hipotesa, hasil tes dan pengukuran yang telah diolah melalui rumus statistik menunjukkan deskripsi data sebagai berikut:

\begin{tabular}{|c|c|c|c|c|}
\hline \multirow[b]{3}{*}{ Deskripsi data } & \multicolumn{4}{|c|}{ Hasil Passing Atas } \\
\hline & \multicolumn{2}{|c|}{ Passing Berpasangan } & \multicolumn{2}{|c|}{ Passing Ke Dinding } \\
\hline & Pre-Test & Post-test & Pre-Test & Post-Test \\
\hline Rentang & $10-32$ & $15-35$ & $10-25$ & $15-27$ \\
\hline Nilai Rata-Rata & 18,5 & 22,16 & 17,16 & 21,66 \\
\hline Simpangan Baku & 7,99 & 7,73 & 5,97 & 6,91 \\
\hline Beda Rata-Rata & \multicolumn{2}{|c|}{3,66} & \multicolumn{2}{|c|}{4,5} \\
\hline S.Baku Beda & \multicolumn{2}{|c|}{0,81} & \multicolumn{2}{|c|}{3,20} \\
\hline$t_{\text {hitung }}$ & \multicolumn{2}{|c|}{11,09} & \multicolumn{2}{|c|}{3,43} \\
\hline $\mathrm{t}_{\text {tabel }}$ & \multicolumn{2}{|c|}{2,57} & \multicolumn{2}{|c|}{2,57} \\
\hline S. Baku Gabungan & \multicolumn{4}{|c|}{7,33} \\
\hline$t_{\text {hitung }}$ & \multicolumn{4}{|c|}{0,11} \\
\hline$t_{\text {tabel }}$ & \multicolumn{4}{|c|}{2,23} \\
\hline
\end{tabular}

Table 1: Hasil Pre-Test dan Post Test Hasil Passing Atas

Dari hasil pre-test kelompok latihan passing atas berpasangan terhadap hasil passing atas dengan $\mathrm{n}=6$ diperoleh rentang 10-32 dengan rata-rata 18,5 dengan simpangan baku 7,99. Dari hasil post-test kelompok latihan passing atas berpasangan terhadap hasil passing atas dengan $\mathrm{n}$ $=6$ diperoleh rentang antara 15-35 dengan rata-rata 22,16 dengan simpangan baku 7,73. Dari rata-rata pre-test dan post-test di dapat nilai beda 3,66 dengan simpangan baku beda 0,81 . Dari hasil pre-test kelompok latihan passing atas kedinding terhadap hasil passing atas dengan $\mathrm{n}=6$ diperoleh rentang antara 10-25 dengan rata-rata 17,16 dengan simpangan baku 5,97. Dari hasil post-test kelompok latihan passing atas ke dinding terhadap hasil passing atas dengan $\mathrm{n}=6$ diperoleh rentang antara 15-27 dengan rata-rata 21,66 dengan simpangan baku 6,91. Dari ratarata pre-test dan post-test di dapat nilai beda 4,5 dengan simpangan baku beda 3,20. 
Dari pengolahan data akhir antar kelompok latihan passing atas berpasangan dan kelompok latihan passing atas kedinding terhadap hasil passing atas di dapat nilai simpangan baku gabungan 7,33 .

Uji Normalitas

Pengujian normalitas data dengan menggunakan uji liliefors, dari kolom daftar pre-test latihan passing atas berpasangan untuk hasil passing atas di dapat $\mathrm{L}_{0}=0,2123$ danL $\mathrm{L}_{\text {tabel }}=0,319$ dengan $\mathrm{n}=6$ dan taraf nyata $\alpha=0,05$. Karena $\mathrm{L}_{\text {hitung }}<\mathrm{L}_{\text {tabel }}$ dapat disimpulkan bahwa sampel dari populasi yang normal. Dari kolom daftar post-test latihan passing atas berpasangan untuk hasil passing atas didapat $\mathrm{L}_{\mathrm{o}}=0,2454$ dan $\mathrm{L}_{\text {tabel }}=0,319$ dengan $\mathrm{n}=6$ dan taraf nyata $\alpha=0,05$. Karena $\mathrm{L}_{\text {hitung }}<\mathrm{L}_{\text {tabel }}$ dapat disimpulkan bahwa sampel berasal dari populasi yang normal. Dari kolom daftar pre-test latihan passing atas ke dinding untuk hasil passing atas didapat $\mathrm{L}_{\mathrm{o}}=$ 0,1406 dan $\mathrm{L}_{\text {tabel }}=0,319$ dengan $\mathrm{n}=6$ dan taraf nyata $\alpha=0,05$. Karena $\mathrm{L}_{\text {hitung }}<\mathrm{L}_{\text {tabel }}$ dapat disimpulkan bahwa sampel berasal dari populasi yang normal. Dari kolom daftar post-test latihan passing atas ke dinding untuk hasil passing atas didapat $\mathrm{L}_{0}=0,2648$ dan $\mathrm{L}_{\text {tabel }}=0,319$ dengan $\mathrm{n}=6$ dan taraf nyata $\alpha=0,05$. Karena $\mathrm{L}_{\text {hitung }}<\mathrm{L}_{\text {tabel }}$ dapat disimpulkan bahwa sampel berasal darim populasi yang normal.

Tabel 2: Hasil Uji Normalitas

\begin{tabular}{|c|c|c|c|c|c|c|c|}
\hline \multirow{5}{*}{$\begin{array}{l}\text { Hasil } \\
\text { Passing } \\
\text { Atas }\end{array}$} & $\begin{array}{l}\text { Kelompok } \\
\text { Latihan }\end{array}$ & $\begin{array}{c}\text { Rata-Rata dan } \\
\text { S. Baku } \\
\text { Pre-test }\end{array}$ & $\mathrm{L}_{\mathrm{o}}$ & $\mathrm{L}_{\text {tabel }}$ & A & $\mathrm{N}$ & Ket \\
\hline & $\begin{array}{l}\text { Kelompok } \\
\text { Latihan } \\
\text { Passing }\end{array}$ & $\begin{array}{c}\bar{X}=18,5 \\
S=7,99 \\
\text { Post-test }\end{array}$ & 0,2123 & 0,319 & 0,05 & $\mathrm{n}=6$ & Normal \\
\hline & $\begin{array}{c}\text { Atas } \\
\text { Berpasangan }\end{array}$ & $\begin{array}{c}\overline{\mathrm{X}}=22,16 \\
\mathrm{~S}=7,73 \\
\text { Pre-test }\end{array}$ & 0,2454 & 0,319 & 0,05 & $\mathrm{n}=6$ & Normal \\
\hline & $\begin{array}{l}\text { Kelompok } \\
\text { Latihan } \\
\text { Passing }\end{array}$ & $\begin{array}{c}\overline{\mathrm{X}}=17,16 \\
\mathrm{~S}=5,97 \\
\text { Post-test }\end{array}$ & 0,1406 & 0,319 & 0,05 & $\mathrm{n}=6$ & Normal \\
\hline & Ke Dinding & $\begin{array}{c}\bar{X}=21,66 \\
S=6,91\end{array}$ & 0,2648 & 0,319 & 0,05 & $\mathrm{n}=6$ & Normal \\
\hline
\end{tabular}

Uji Homogenitas

Uji homogenitas data pre-test untuk hasil passing atas antara kelompok latihan passing atas berpasangan dan passing atas ke dinding didapat $\mathrm{F}_{\text {hitung }}=1,06$ diketahui bahwa $\mathrm{n}_{1}-1=6-1=5$ dan $\mathrm{n}_{2}-1=6-1=5$, sehingga didapat $\mathrm{F}_{\text {tabel }}=5,05$ pada taraf nyata $\alpha=0,05$ maka $\mathrm{F}_{\text {hitung }}<\mathrm{F}_{\text {tabel }}$ $(1,06<5,05)$. Dapat disimpulkan bahwa kedua variana dalah homogen. Uji homogenitas data post-test untuk hasil passing atas antara kelompok latihan passing atas berpasangan dan passing atas ke dinding didapat $\mathrm{F}_{\text {hitung }}=0,74$ diketahui bahwa $\mathrm{n}_{1^{-}}-1=6-1=5$ dan $\mathrm{n}_{2}-1=6-1=5$, sehingga didapat $F_{\text {tabel }}=5,05$ pada taraf nyata $\alpha=0,05$ maka $F_{\text {hitung }}<F_{\text {tabel }}(0,74<5,05)$. Dapat disimpulkan bahwa kedua varian adalah homogen. Uji homogenitas data pre-test untuk hasil passing atas antara kelompok latihan passing atas berpasangan dan data post-test untuk hasil passing atas kelompok latihan passing atas ke dinding didapat $\mathrm{F}_{\text {hitung }}=1,33$ diketahui bahwa $\mathrm{n}_{1^{-}}$ $1=6-1=5$ dan $\mathrm{n}_{2}-1=6-1=5$, sehingga didapat $\mathrm{F}_{\text {tabel }}=5,05$ pada taraf nyata $\alpha=0,05$ maka $\mathrm{F}_{\text {hitung }}<$ $\mathrm{F}_{\text {tabel }}(1,33<5,05)$. Dapat disimpulkan bahwa kedua varian adalah homogen.

Uji Hipotesis

Dari hasil perhitungan data hasil passing atas kelompok latihan passing atas berpasangan diperoleh $\mathrm{t}_{\text {hitung }}=11,09$. Dari daftar distribusi $\mathrm{t}$ dengan menggunakan peluang $1-1 / 2 \alpha=0,975$ dengan $\mathrm{dk} n-1=5$ diperoleh harga $\mathrm{t}_{(0,975)}=2,57$. Dalam criteria pengujian hipotesis dinyatakan 
bahwa padat ${ }_{\text {hitung }}>\mathrm{t}_{\text {tabel }}$ dengan $\alpha=0,05$ maka $\mathrm{H}_{\mathrm{o}}$ ditolak dan $\mathrm{H}_{\mathrm{a}}$ diterima dimana 11,09 $>$ 2,57. Maka dapat disimpulkan bahwa terdapat pengaruh yang signifikan dari latihan passing atas berpasangan terhadap hasil passing atas bola voli pada siswa putra ekstrakurikuler SMA Negeri 1 Sei Suka Tahun 2020. Dari hasil perhitungan data hasil passing atas kelompok latihan passing atas ke dinding diperoleh $\mathrm{t}_{\text {hitung }} 3$ 3,43. Dari daftar distribusi $\mathrm{t}$ dengan menggunakan peluang $1-1 / 2 \alpha=0,975$ dengan $\mathrm{dk} n-1=5$ diperoleh harga $\mathrm{t}_{(0,975)}=2,57$. Dalam kriteria pengujian hipotesis dinyatakan bahwa pada $t_{\text {hitung }}>t_{\text {tabel }}$ dengan $\alpha=0,05$ maka $\mathrm{H}_{\mathrm{o}}$ ditolak dan $\mathrm{H}_{\mathrm{a}}$ diterima dimana 3,43>2,57.

Maka dapat disimpulkan bahwa terdapat pengaruh yang signifikan dari latihan passing atas ke dinding terhadap hasil passing atas bola voli pada siswa putra ekstrakurikuler SMA Negeri 1 Sei Suka Tahun 2020. Dari hasil uji t data post-test hasil passing atas antara kelompok latihan passing atas berpasangan dan latihan passing atas ke dinding diperoleh t-hitung $=0,11$. Dari daftar distribusi t dengan menggunakan peluang $1-1 / 2 \alpha=0,975$ dengan $d k n_{1}+n_{2}-2=10$ diperoleh harga $\mathrm{t}_{(0,975)}=2,23$. Dalam kriteria pengujian hipotesis menyatakan bahwa pada $\mathrm{t}_{\text {hitung }}$ $<\mathrm{t}_{\text {tabel }}$ dengan $\alpha=0,05$ maka $\mathrm{H}_{\mathrm{o}}$ diterima dan $\mathrm{H}_{\mathrm{a}}$ ditolak dimana $0,11<2,23$. Maka dapat disimpulkan bahwa latihan passing atas berpasangan tidak lebih besar pengaruhnya daripada latihan passing atas ke dinding terhadap hasil passing atas bola voli pada siswa putra ekstrakurikuler SMA Negeri 1 Sei Suka Tahun 2020.

\section{SIMPULAN}

Berdasarkan hasil pengujian hipotesis dan pembahasan hasil penelitian, maka peneliti dapat menarik beberapa kesimpulan sebagai berikut; terdapat pengaruh yang signifikan dari passing atas berpasangan terhadap hasil passing atas bola voli siswa putra ekstrakurikuler SMA Negeri 1 Sei Suka Tahun 2020, terdapat pengaruh yang signifikan dari latihan passing atas ke dinding terhadap hasil passing atas pada siswa putra ekstrakurikuler SMA Negeri 1 Sei Suka Tahun 2020, dan latihan passing atas berpasangan tidak lebih besar pengarunya dari pada latihan passing atas ke dinding terhadap hasil passing atas pada siswa putra ekstrakurikuler SMA Negeri 1 Sei Suka Tahun 2020.

\section{DAFTAR PUSTAKA}

Ahmadi, Nuril. (2007). Panduan olahraga bola voli. Solo: Era Pustaka Utama.

Arikunto, Suharsimi. (1998). Prosedur Penelitian Suatu Pendekatan Praktik. Jakarta: PT Rineka Cipta.

Beutelstahl, Dieter. (1978). Belajar Bermain Bola Voli. Bandung: CV Pioner Jaya.

Bompa, Tudor O. Theory And Methodology Of Training. Surabaya: Universitas Airlangga.

Harsono. (1988). Coaching dan Aspek-Aspek Psikologi Dalam Coaching. Jakarta. Departemen Pendidikan dan Kebudayaan.

Kleinmann, T,. \& Dieter, Kruber. (1986). Technik; Taktik und Konditionsschulung volleyball. Jakarta: PT Gramedia.

Muhajir,. \& Graha, Ali Satia .(2011). Pendidikan Jasmani Olahraga dan Kesehatan. Jakarta: Yudistira

Muhajir. (2004). Pendidikan Jasmani, Teori dan Praktek. Bandung: Erlangga

Nossek, Yosef. (1982). Teori umum latihan. Lagos: Institut Nasional Olahraga.

Roji. (2009). Pendidikan Jasmani Olahraga dan Kesehatan. Jakarta: Erlangga.

Sudjana. (2002). Metode Statistika. Bandung: PT Tarsito.

Sunarno, Agung. (2012). Tes, Pengukuran, dan Evaluasi Keolahragaan. Medan: Universitas Negeri Medan.

Sunarno, Agung., Sihombing, R., \& Syaifullah, D. (2011). Metode Penelitian Keolahragaan. Solo: Yuma Pustaka.

Viera, Barbara L. (2000). Bola Voli Tingkat Pemula. Jakarta: PT Raja Grafindo Persada. 